OPEN ACCESS

Edited by:

Angel Lanas,

University of Zaragoza, Spain

Reviewed by:

Magdy El-salhy,

University of Bergen, Norway

Song Jin,

The Teaching Hospital of Chengdu

University of Traditional Chinese

Medicine, China

*Correspondence: Bodil Ohlsson

bodil.ohlsson@med.lu.se

Specialty section: This article was submitted to

Gastroenterology

a section of the journal

Frontiers in Medicine

Received: 27 December 2020

Accepted: 12 July 2021

Published: 01 September 2021

Citation:

Nilsson D and Ohlsson B (2021) Gastrointestinal Symptoms and

Irritable Bowel Syndrome Are Associated With Female Sex and Smoking in the General Population and With Unemployment in Men.

Front. Med. 8:646658.

doi: 10.3389/fmed.2021.646658

\section{Gastrointestinal Symptoms and Irritable Bowel Syndrome Are Associated With Female Sex and Smoking in the General Population and With Unemployment in Men}

\author{
Daniel Nilsson and Bodil Ohlsson* \\ Department of Internal Medicine, Skåne University Hospital, Lund University, Malmö, Sweden
}

Background: The influence of daily life exposure on the gastrointestinal tract is not fully understood. This study aimed to examine associations between functional gastrointestinal symptoms and sociodemographic status and lifestyle habits in the general population.

Methods: The Malmö Offspring Study (MOS) included 2,648 participants from the general population who had answered a questionnaire about sociodemographic status, lifestyle habits, medical health, and self-reported irritable bowel syndrome (IBS). The visual analog scale for IBS (VAS-IBS) was completed to assess gastrointestinal symptoms the past 2 weeks. Subjects with organic gastrointestinal diseases were excluded. Presence of self-reported IBS and gastrointestinal symptoms the past 2 weeks were used as dependent variables to study the associations with age, sex, body mass index, education, occupation, marital status, smoking, snuff using, alcohol drinking frequency, alcohol amount per drinking occasion, physical activity at work, and physical activity during leisure time, using logistic regression and generalized linear model.

Results: Self-reported IBS was associated with gastrointestinal symptoms the past 2 weeks $(\rho<0.001)$. There was an association between IBS and female sex $(p<0.001)$, former smoking $(p<0.001)$, present smoking $(p<0.001)$, and an inverse association with drinking $3-4$ standard glasses per occasion $(p=0.038)$. Gastrointestinal symptoms were associated with age $50-59$ years $(p=0.009), \geq 60$ years $(p=0.004)$, female sex $(p<0.001)$, studying $(p=0.036)$, unemployment $(p$ $=0.009)$, former smoking $(p=0.001)$, and present smoking $(p=0.012)$. In men, IBS was associated with middle-age and both IBS and gastrointestinal symptoms were associated with unemployment $(p<0.001$ and $p=0.001$, respectively). In women, IBS was associated with present smoking $(p=0.022)$, and gastrointestinal symptoms were associated with former smoking and inversely associated with higher age $(p=0.006)$ and intermediate physical activity at work $(p=0.008)$. No associations were found with BMl, education, marital status, or snuff using. 
Conclusion: Self-reported IBS in the general population shows strongest association with female sex and smoking, whereas gastrointestinal symptoms also are associated with unemployment and inversely associated with higher age. In men, both IBS and gastrointestinal symptoms are associated with unemployment. In women, both IBS and gastrointestinal symptoms are associated with smoking, whereas symptoms are inversely associated with higher age and intermediate physical activity.

Keywords: irritable bowel syndrome, gastrointestinal symptoms, lifestyle habits, population-based, sociodemography, smoking, snuff, unemployment

\section{INTRODUCTION}

The mechanism behind the functional gastrointestinal disorders (FGIDs) is unclear, and many factors such as low-grade inflammation, dysbiosis of the gut microbiota, and psychological factors are discussed as etiological factors $(1,2)$. Irritable bowel syndrome (IBS) is the most common of the FGIDs (2). The prevalence of IBS varies between different versions of the Rome criteria but may occur in around $5-11 \%$ of the population $(3,4)$. Besides complaining of the symptoms, the disease is also a common reason for staying at home from work or school $(5,6)$. The symptoms are treated with dietary advice, psychological treatment, and drugs to relief symptoms (2). Although IBS is the most common disease at a Department of Gastroenterology, most of the patients are handled at primary healthcare centers or do not visit any physician at all (1). Still, most of the research in this entity is performed on patients from tertiary care centers.

Regarding the associations between IBS and sociodemographic factors and lifestyle habits, the results are contradictory depending on country; sample composition and sample size; and Rome criteria used. It is well-described that IBS is associated with female sex $(2,7)$, whereas there has not been found any significant difference in IBS prevalence regarding age and socioeconomic factors in a large meta-analysis (7). Female patients with IBS in Iran were more often single and being unemployed than patients without IBS (8), whereas married or single subjects in a Bulgarian population-based study had lower IBS prevalence than those only living in a relationship (9). An inverse association between IBS and body mass index (BMI) was observed in men in one large French study (10), with no association between IBS and BMI when calculations were performed with both sexes together (9-11).

In a systematic review, a weak association between smoking and FGIDs were observed; the association was varying dependent on different criteria for FGID (12). In contrast, we have previously shown in a population-based study of middle-age and elder subjects, that smoking was associated with several functional gastrointestinal (GI) symptoms (13). The role of alcohol has been even more difficult to determine, showing no association $(14,15)$, a tendency toward less symptoms with a moderate alcohol intake (13), or aggravated symptoms after high intake of alcohol $(12,15)$. On the other hand, a higher prevalence of IBS was found in non-users of alcohol in a population-based Bulgarian study (9). The role of snuff, a Swedish variant of tobacco, has not been examined regarding its association with
FGIDs. Higher physical activity was associated with less GI symptoms in middle-age and elder Swedish subjects from the general population (11).

Our hypothesis was that smoking and snuff using have similar adverse impact on GI symptoms and that higher alcohol consumption, living alone, and lower BMI, education, and physical activity are all associated with more GI symptoms. The aim in this population-based cohort was to examine association of self-reported IBS and GI symptoms the past 2 weeks with sociodemographic factors and lifestyle habits.

\section{MATERIALS AND METHODS}

The study was conducted according to the Declaration of Helsinki and approved by the Regional Ethics Review Board in Lund (2012/594). Written, informed consent was given by all participants prior to study start.

\section{Study Participants}

The Malmö Diet and Cancer Study (MDCS) invited all subjects born between 1923 and 1950, and living in Malmö between 1991 and 1996, to take part in the study. A total of 28,098 patients completed all tests (16). Later, 6,103 individuals were reexamined for assessing cardiovascular risk factors and constitutes the Malmö Diet and Cancer Cardiovascular Cohort (MDC-CC) (17). The Malmö Offspring Study (MOS) is a population-based cohort consisting of children and grandchildren to participants in the MDC-CC (18). Subjects were invited to an anthropometric and clinical examination including a measurement of weight and height. From the total of 4225 participants included in June 2020 (inclusion rate 47\%), 1,577 were excluded due to organic bowel diseases such as celiac disease, Crohn's disease, ulcerative colitis, lactose intolerance, reflux, and/or ulcer, or due to that they had not answered the questions regarding GI symptoms. Thus, 2,648 individuals were finally included in the present study (Figure 1).

\section{Study Questionnaire}

The MOS included a web-based survey with questions regarding living conditions, education, occupation, tobacco, alcohol, physical activity, medical health, heredity, and medication. The participants were interpreted as having self-reported IBS according to Rome III criteria (19) if they answered "yes" to the following question: "Have you several times during a month suffered from abdominal pain related to irregular bowel habits which is called IBS?" 


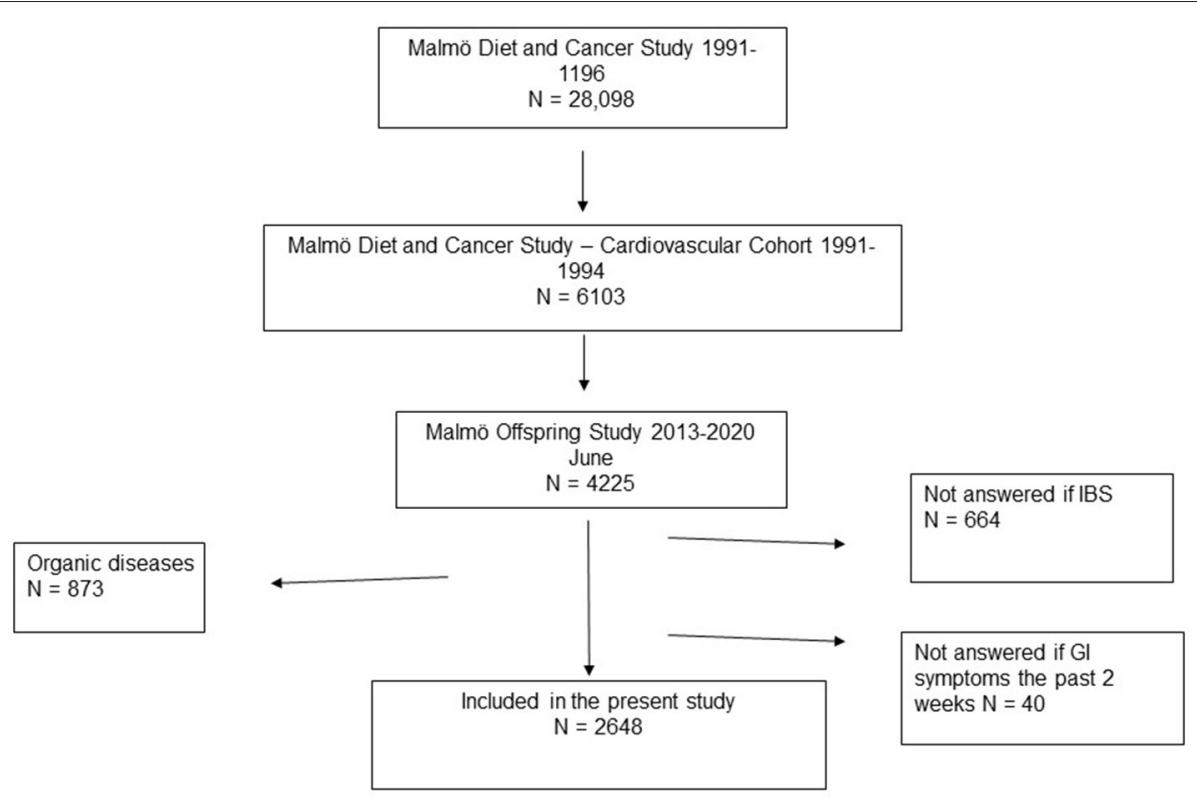

FIGURE 1 | The diagram shows the origin of the participants. Malmö Diet and Cancer Study invited everyone living in Malmö between 1991 and 1996 and were born between 1923 and 1950. A total of 28,098 patients completed all tests. A subcategory, the cardiovascular cohort, was extracted from those participants, containing a total of 6,103 randomly selected patients who participated between the years 1991 and 1994. Malmö Offspring Study (MOS) was a population-based cohort consisting of children and grandchildren to someone who was included in the MDC-CC. This study cohort included those from MOS who had answered the following two questions: "Do you several times a month suffer from abdominal pain and irregular bowel habits known as IBS?" and "Have you experienced bowel symptoms during the past 2 weeks?" Participants with any organic gastrointestinal diseases (celiac disease, Crohn's disease, ulcerative colitis, lactose intolerance, reflux, and ulcer) were excluded.

\section{Visual Analog Scale for Irritable Bowel Syndrome}

The participants were asked: "Have you experienced GI symptoms the past 2 weeks?" If they answered "yes" to this question, they were encouraged to complete the validated visual analog scale for irritable bowel syndrome (VAS-IBS) regarding GI symptoms the last 2 weeks (20). The VAS-IBS assesses the degree of abdominal pain, diarrhea, constipation, bloating and flatulence, vomiting and nausea, intestinal symptom's influence on daily life, and psychological well-being on scales ranging from 0 to $100 \mathrm{~mm}$, where a higher value means more symptoms. The scales were inverted from the original version (20).

\section{Data Categorization and Modifications}

Age was divided into $<30,30-39,40-49,50-59$, or $\geq 60$ years. Sex was divided into men and women. BMI was grouped according to the World Health Organization (WHO) standard into normal or underweight $\left(<25 \mathrm{~kg} / \mathrm{m}^{2}\right)$, overweight $(25.0-$ $\left.29.9 \mathrm{~kg} / \mathrm{m}^{2}\right)$, and obesity $\left(\geq 30 \mathrm{~kg} / \mathrm{m}^{2}\right)(21)$. Education was divided into primary school or less, secondary school, and higher education. Marital status was divided into those who lived alone, those who lived together with someone, and a separate group for others. Occupation was divided into working, studying, sick leave, unemployment, retirement, or other, where the category other was not further defined. Participants who had chosen several alternatives were classified as missing values. Smoking and snuff using were grouped into never, former, or present users.
Drinking frequency last year was separated into $\leq 1$ time/month, 2-4 times per month, $2-3$ times/week, $\geq 4$ times/week. Drinking amount per occasion was defined with standard glasses (12 grams alcohol) and divided into 1-2, 3-4, 5-6, 7-9, or $\geq 10$ glasses. Physical activity at work last year was separated into light (mostly stationary to standing with light muscle activity, e.g., eating and washing-up), intermediate (muscle activity with intermediate intensity, e.g., walking and cleaning), and hard (heavy muscle activity, e.g., gardening). Physical activity during leisure time last year was grouped into sedentary to moderate (reading, watching tv, biking, and moving without sweating), or training regularly (exercise $>30$ min twice a week or participating in sports).

\section{Statistical Analysis}

IBM SPSS (Statistical Product and Service Solutions) version 26 for Windows was used to perform the statistical calculations. Data were analyzed with KS-test (Kolmogorov-Smirnov) and histograms to test for normal distribution for the scaled variables. None of the parameters followed a normal distribution and data is therefore presented as median and interquartiles or number and percentages. Pearson Chi-square test was used for calculations on dichotomous variables to determine differences between sexes and between the study groups IBS/no IBS and GI symptoms the past 2 weeks/no GI symptoms.

Logistic regression was used to examine the associations between self-reported IBS and GI symptoms with 
TABLE 1 | Distribution of gastrointestinal symptoms.

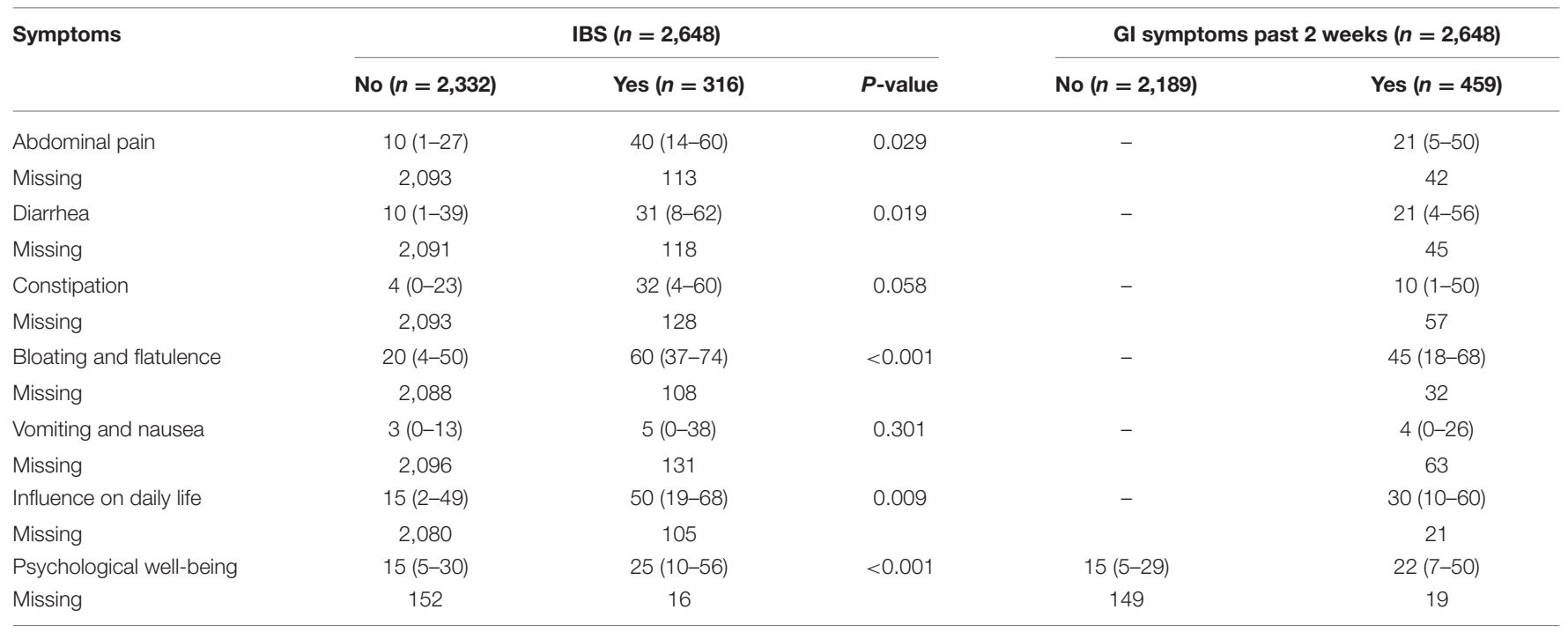

GI, gastrointestinal; IBS, self-reported irritable bowel syndrome. Symptoms the past 2 weeks were assessed by the visual analog scale for irritable bowel syndrome (VAS-IBS) where O mm means no symptoms and $100 \mathrm{~mm}$ means maximal symptoms (22). Values are presented as median and 25th-75th percentile. Participants who answered "No" to question about having any Gl symptoms the past 2 weeks were only supposed to answer the last question (psychological well-being). Mann-Whitney U-test. P<0.05 was considered statistically significant.

sociodemographic status and lifestyle factors, with IBS or GI symptoms the past 2 weeks as dependent variables and age, sex, BMI, education, occupation, marital status, smoking, snuff using, drinking frequency past year, drinking amount per occasion, physical activity at work last year, and physical activity during leisure time last year as independent variables. Crude Odds Ratio (OR) and 95\% confidence interval (CI) were calculated for each variable. Adjusted OR were then calculated, adjusted for the significant parameters in the crude calculations, i.e., age, sex, smoking, drinking frequency past year and drinking amount per occasion for IBS and age, sex, BMI, education, occupation, smoking, and drinking frequency for GI symptoms. The lowest group, men (sex), or those who never used substances (tobacco or snuff), were used as reference values. To test for sex interaction (i), a multiplicative variable (e.g., sex ${ }^{\mathrm{x}}$ age groups) was added in the adjusted models with all variables. Separate logistic regressions based on sex were conducted, first to calculate crude OR and then adjusted for age and occupation in men and smoking and snuff for women concerning the presence of IBS, and adjusted for age, BMI, and occupation in men and age, occupation, smoking, and physical activity at work in women concerning the presence of GI symptoms.

Generalized linear model was used to examine the association between self-reported IBS and GI symptoms according to the VAS-IBS, with previously found significant parameters as predictors (sex, smoking, drinking frequency, and drinking amount per occasion), and between specific GI symptoms according to the VAS-IBS and age, sex, occupation and smoking, which were significantly associated with GI symptoms in the logistic regression. Values are presented as $\beta$ (beta-value) and 95\% CI. $P<0.05$ considered as statistically significant.
TABLE 2 | Associations between gastrointestinal symptoms the past 2 weeks and having IBS.

\begin{tabular}{lccc}
\hline Symptoms & $\boldsymbol{\beta}$ & $\mathbf{9 5 \%} \mathbf{C l}$ & $\boldsymbol{P}$-value \\
\hline Abdominal pain & 22.332 & $15.017-29.647$ & $<0.001$ \\
Diarrhea & 29.016 & $21.276-36.757$ & $<0.001$ \\
Constipation & 10.623 & $2.767-18.479$ & 0.008 \\
Bloating and flatulence & 22.721 & $14.820-30.622$ & $<0.001$ \\
Vomiting and nausea & 14.918 & $7.767-22.069$ & $<0.001$ \\
Influence on daily life & 28.531 & $20.541-36.521$ & $<0.001$ \\
Psychological well-being & 20.579 & $18.200-22.957$ & $<0.001$
\end{tabular}

$\beta$, beta-value; $\mathrm{Cl}$, confidence interval. Symptoms the past 2 weeks were assessed by the visual analog scale for irritable bowel syndrome (VAS-IBS) where $0 \mathrm{~mm}$ means no symptoms and $100 \mathrm{~mm}$ means maximal symptoms (20).

Generalized linear model, adjusted for sex, smoking, drinking frequency, and drinking amount per occasion. $P<0.05$ was considered as statistically significant.

\section{RESULTS}

\section{Population Characteristics}

Of the 2,648 participants included (1,391 women [52.5\%]), 316 participants (11.9\%) had self-reported IBS, and 459 participants (17.3\%) had experienced GI symptoms in the past 2 weeks. Those with IBS had more symptoms than those without IBS (Table 1), and there was a strong association between all individual symptoms and self-reported IBS (Table 2). The participants with IBS were $43.38(29.34-52.52)$ years old and had a BMI of 24.54 $(22.27-27.63) \mathrm{kg} / \mathrm{m}^{2}$, and those without IBS were $45.59(29.28-$ $54.86)$ years old and had a BMI of $25.22(22.76-28.38) \mathrm{kg} / \mathrm{m}^{2}$ ( $p=0.128$ and $p=0.011$, respectively). The age in those who had GI symptoms the past 2 weeks was 40.50 (27.58-51.22) years and the BMI was $24.30(22.13-27.82) \mathrm{kg} / \mathrm{m}^{2}$, in comparison 
TABLE 3 | Association between sociodemographic factors, lifestyle habits, and IBS.

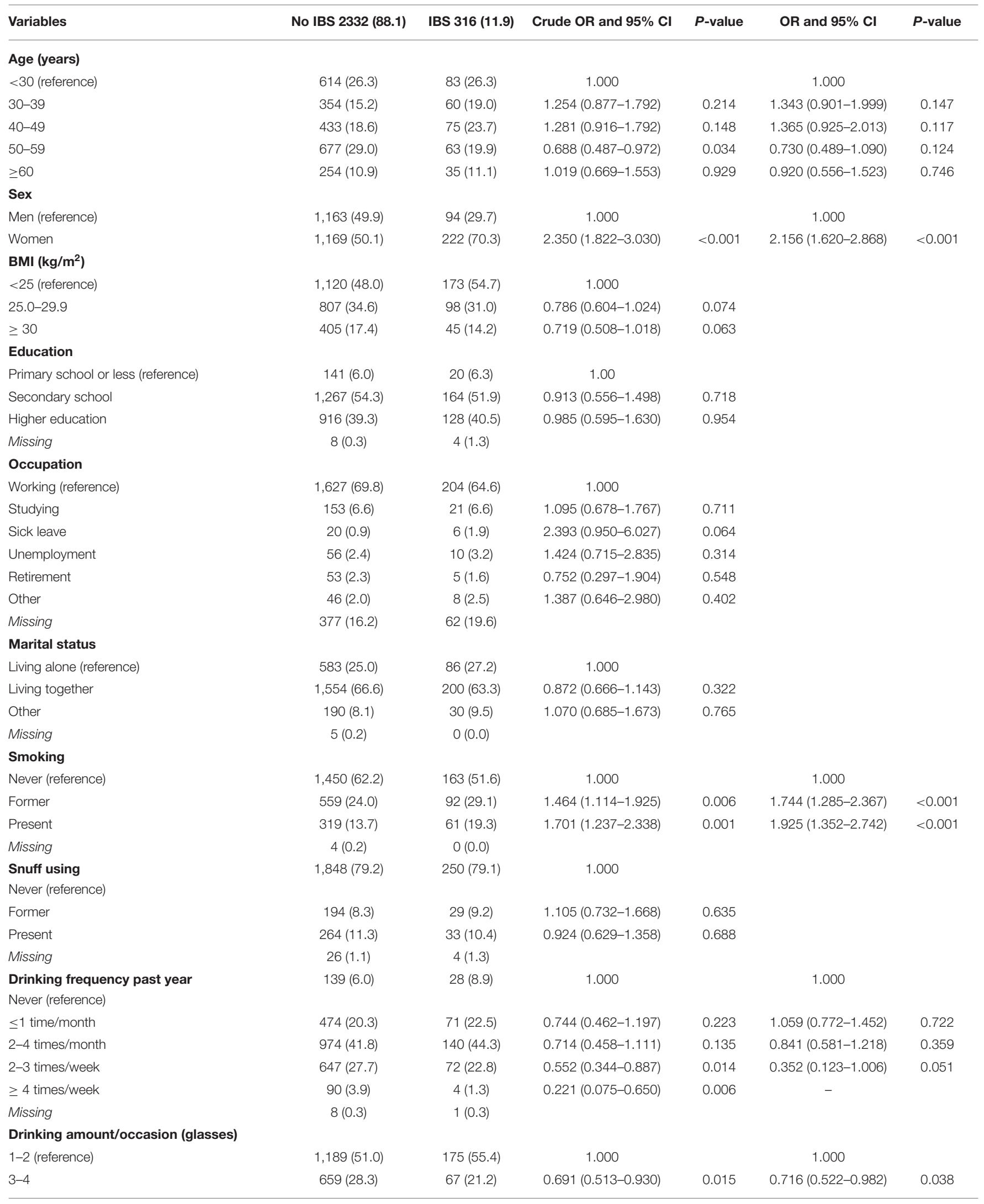


TABLE 3 | Continued

\begin{tabular}{|c|c|c|c|c|c|c|}
\hline Variables & No IBS 2,332 (88.1) & IBS 316 (11.9) & Crude OR and $95 \% \mathrm{Cl}$ & $P$-value & OR and $95 \% \mathrm{Cl}$ & $P$-value \\
\hline $5-6$ & $221(9.5)$ & $31(9.8)$ & 0.953 (0.634-1.433) & 0.817 & $1.036(0.659-1.628)$ & 0.878 \\
\hline $7-9$ & 90 (3.9) & $10(3.2)$ & 0.755 (0.385-1.479) & 0.412 & $0.929(0.448-1.927)$ & 0.843 \\
\hline$\geq 10$ & $23(1.0)$ & $4(1.3)$ & $1.182(0.404-3.457$ & 0.761 & $1.661(0.535-5.162)$ & 0.380 \\
\hline Missing & $150(6.4)$ & $29(9.2)$ & & & & \\
\hline \multicolumn{7}{|l|}{ Physical activity at work } \\
\hline Light (reference) & 1,349 (57.8) & 178 (56.3) & 1.000 & & & \\
\hline Intermediate & $581(24.9)$ & $77(24.4)$ & $1.004(0.756-1.335)$ & 0.976 & & \\
\hline Hard & 323 (13.9) & 42 (13.3) & 0.985 (0.689-1.409) & 0.936 & & \\
\hline Missing & $79(3.4)$ & $19(6.0)$ & & & & \\
\hline \multicolumn{7}{|c|}{ Physical activity during leisure time } \\
\hline Sedentary to moderate (reference) & $373(16.0)$ & $60(19.0)$ & 1.000 & & & \\
\hline Training regularly & $876(37.6)$ & $121(38.3)$ & $0.859(0.616-1.197)$ & 0.369 & & \\
\hline Missing & $1,083(46.4)$ & $135(42.7)$ & & & & \\
\hline
\end{tabular}

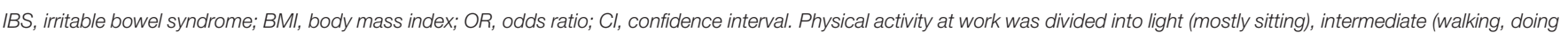

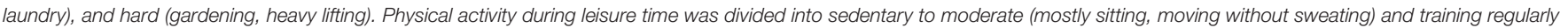

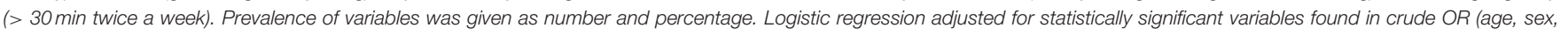
smoking, drinking frequency past year, and drinking amount per occasion). $P<0.05$ was considered statistically significant.

to $46.18(29.75-55.15)$ years and $25.25(22.84-28.39) \mathrm{kg} / \mathrm{m}^{2}$ in those without symptoms ( $p<0.001$ and $p=0.001$, respectively). Subjects with self-reported IBS were more prevalent in lower age groups $(p=0.005)$, were more often women $(p<0.001)$ and smokers $(p=0.001)$ and drank alcohol less often $(p=0.014)$ than those without IBS (Table 3). Subjects with GI symptoms the past 2 weeks were more prevalent in lower age groups $(p<$ $0.001)$, were more often women $(p<0.001)$, unemployed or sick $(p=0.003)$, and smokers $(p=0.008)$, and had lower BMI $(p=$ $0.015)$ and education degree $(p=0.05)$, than those without GI symptoms (Table 4). The 297 present snuff users were most often found in the group of former smokers $(n=124)$ and least often in the group of present smokers $(n=72)(p<0.001)$.

\section{Association Between IBS, Gastrointestinal Symptoms the Past 2 Weeks and Sociodemographic Factors and Lifestyle Habits}

There was a significant association between IBS and female sex (OR: 2.156; 95\% CI: 1.620-2.868; $p<0.001$ ), former smoking (OR: 1.744; 95\% CI:1.285-2.367; $p<0.001$ ), and present smoking (OR: 1.925; 95\% CI: 1.352-2.742; $p<0.001$ ), and an inverse association with drinking frequency of $2-3$ times a week (OR: 0.352; 95\% CI: 0.123-1.006; $p=0.051)$ and drinking 3-4 standard glasses per occasion (OR: 0.716 ; $95 \% \mathrm{CI}: 0.522-0.982 ; p=0.038$ ) (Figure 2, Table 3).

Having GI symptoms the past 2 weeks was associated with female sex (OR: 1.770; 95\% CI: 1.387-2.259; $p<0.001$ ), studying (OR: $1.597 ; 95 \%$ CI: $1.031-2.473 ; p=0.036$ ), unemployment (OR: 2.143 ; 95\% CI: $1.207-3.804 ; p=0.009$ ), former smoking (OR 1.518; 95\% CI: $1.148-2.007 ; p=0.003$ ), and present smoking (OR: $1.479 ; 95 \% \mathrm{CI} ; 1.055-2.072 ; p=0.023$ ), whereas it was inversely associated with age 50-59 years (OR: 0.603; 95\% CI:
$0.412-0.883 ; p=0.009)$ and age $\geq 60$ years (OR: $0.384 ; 95 \% \mathrm{CI}$ : $0.202-0.733 ; p=0.004$ ) (Figure 3, Table 4).

When examining the degree of severity of each specific GI symptom and the significant parameters from the logistic regression, i.e., age, sex, occupation, and smoking, higher age was associated with better psychological well-being. Female sex was associated with all GI symptoms, except diarrhea and vomiting and nausea, and worse psychological well-being. Present smoking was associated with more symptoms and worse psychological well-being. Former smoking was only associated with bloating and flatulence ( $\beta$ : 7.531; 95\% CI: $1.370-13.692 ; p=0.017$ ). Studying was associated with more abdominal pain and bloating and flatulence but improved psychological well-being. Sick leave and unemployment were associated with severe symptoms and poor psychological well-being in comparison to working (Table 5).

No statistically significant associations were found between IBS or GI symptoms the past 2 weeks and BMI groups, education, marital status, snuff use, physical activity at work, or physical activity during leisure time (Tables 3,4 ).

\section{Associations Stratified by Sex}

When examining the differences between sex in the present cohort, women had lower BMI group $(p<0.001)$, higher education degree $(p<0.001)$, were more often sick and less often unemployed or retired ( $p=0.008)$, less often snuff users $(p<0.001)$, drank alcohol less often $(p<0.001)$ and in less amounts $(p<0.001)$, and had less physical activity at work ( $p<$ $0.001)$ in comparison to men. Smoking prevalence did not differ between sexes $(p=0.093)$. In the interaction analysis, sick leave was the only parameter which interacted with sex for having IBS ( $\mathrm{pi}=0.021$ ).

In men, there was a significant association between IBS and being 30-49 years old and being unemployed or other (Table 6). Regarding GI symptoms the past 2 weeks, the only association 
TABLE 4 | Association between sociodemographic status, lifestyle habits, and Gl symptoms past 2 weeks.

\begin{tabular}{|c|c|c|c|c|c|c|}
\hline Variables & No Symptoms 2189 (82.7) & Symptoms 459 (17.3) & Crude OR and $95 \% \mathrm{Cl}$ & $P$-value & OR and $95 \% \mathrm{Cl}$ & $P$-value \\
\hline \multicolumn{7}{|l|}{ Age (years) } \\
\hline <30 (reference) & $555(25.4)$ & $142(30.9)$ & 1.00 & & 1.000 & \\
\hline $40-49$ & $403(18.4)$ & $105(22.9)$ & $1.018(0.767-1.351)$ & 0.900 & $1.099(0.756-1.596)$ & 0.622 \\
\hline $50-59$ & $643(29.4)$ & $97(21.1)$ & $0.590(0.445-0.782)$ & $<0.001$ & $0.603(0.412-0.883)$ & 0.009 \\
\hline Men (reference) & $1,099(50.2)$ & $158(34.4)$ & 1.00 & & 1.000 & \\
\hline Women & $1,090(49.8)$ & 301 (65.6) & $1.921(1.557-2.370)$ & $<0.001$ & $1.770(1.387-2.259)$ & $<0.001$ \\
\hline \multicolumn{7}{|l|}{ BMI $\left(\mathrm{kg} / \mathrm{m}^{2}\right)$} \\
\hline$<25$ (reference) & $1,043(47.6)$ & $250(54.5)$ & 1.00 & & 1.000 & \\
\hline $25.0-29.9$ & $773(35.3)$ & $132(28.8)$ & $0.712(0.566-0.897)$ & 0.004 & $0.899(0.688-1.176)$ & 0.437 \\
\hline Secondary school & $1,196(54.6)$ & $235(51.2)$ & $1.385(0.850-2.258)$ & 0.191 & $1.483(0.799-2.750)$ & 0.211 \\
\hline Higher education & $844(38.6)$ & 200 (43.6) & $1.671(1.020-2.735)$ & 0.041 & $1.774(0.942-3.340)$ & 0.076 \\
\hline Missing & $8(0.4)$ & $4(0.9)$ & & & & \\
\hline \multicolumn{7}{|l|}{ Occupation } \\
\hline Working (reference) & $1,536(70.2)$ & 295 (64.3) & 1.00 & & 1.000 & \\
\hline Studying & $132(6.0)$ & $42(9.2)$ & $1.657(1.146-2.396)$ & 0.007 & $1.597(1.031-2.473)$ & 0.036 \\
\hline Sick leave & $20(0.9)$ & $6(1.3)$ & $1.562(0.622-3.923)$ & 0.342 & $1.473(0.565-3.839)$ & 0.428 \\
\hline Unemployment & $47(2.1)$ & $19(4.1)$ & $2.105(1.218-3.638)$ & 0.008 & $2.143(1.207-3.804)$ & 0.009 \\
\hline Retirement & $54(2.5)$ & $4(0.9)$ & $0.386(0.139-1.073)$ & 0.068 & $0.901(0.281-2.892)$ & 0.861 \\
\hline Other & $45(2.1)$ & $9(2.0)$ & $1.041(0.504-2.153)$ & 0.913 & $0.960(0.457-2.020)$ & 0.915 \\
\hline Missing & $355(16.2)$ & $84(18.3)$ & & & & \\
\hline Former & $526(24.0)$ & $125(27.2)$ & $1.283(1.013-1.626)$ & 0.039 & $1.518(1.148-2.007)$ & 0.003 \\
\hline Present & 298 (13.6) & $82(17.9)$ & $1.486(1.124-1.964)$ & 0.005 & $1.479(1.055-2.072)$ & 0.023 \\
\hline Missing & $4(0.2)$ & $0(0.0)$ & & & & \\
\hline \multicolumn{7}{|l|}{ Snuff using } \\
\hline Never (reference) & $1,725(78.8)$ & $373(81.3)$ & 1.00 & & & \\
\hline Former & $188(8.6)$ & $35(7.6)$ & $0.861(0.590-1.256)$ & 0.437 & & \\
\hline Present & $254(11.6)$ & $43(9.4)$ & $0.783(0.556-1.102)$ & 0.161 & & \\
\hline Missing & $22(1.0)$ & $8(1.7)$ & & & & \\
\hline \multicolumn{7}{|c|}{ Drinking frequency past year } \\
\hline Never (reference) & $133(6.1)$ & $34(7.4)$ & 1.00 & & 1.000 & \\
\hline$\leq 1$ time/month & $449(20.5)$ & $96(20.9)$ & $0.836(0.541-1.294)$ & 0.422 & $0.756(0.450-1.270)$ & 0.291 \\
\hline 2-4 times/month & $923(42.2)$ & $191(41.6)$ & $0.809(0.538-1.217)$ & 0.309 & $0.803(0.494-1.306)$ & 0.377 \\
\hline 2-3 times/week & $594(27.1)$ & $125(27.2)$ & $0.823(0.539-1.257)$ & 0.367 & $0.950(0.568-1.587)$ & 0.844 \\
\hline$\geq 4$ times/week & $84(3.8)$ & $10(2.2)$ & $0.466(0.219-0.992)$ & 0.048 & $0.571(0.235-1.384)$ & 0.215 \\
\hline Missing & $6(0.3)$ & $3(0.7)$ & & & & \\
\hline \multicolumn{7}{|c|}{ Drinking amount/occasion (glasses) } \\
\hline 1-2 (reference) & $1,115(50.9)$ & $249(54.2)$ & 1.00 & & & \\
\hline $3-4$ & $615(28.1)$ & $111(24.2)$ & $0.808(0.633-1.032)$ & 0.088 & & \\
\hline $5-6$ & $208(9.5)$ & $44(9.6)$ & 0.947 (0.665-1.348) & 0.764 & & \\
\hline
\end{tabular}


TABLE 4 | Continued

\begin{tabular}{|c|c|c|c|c|c|c|}
\hline Variables & No Symptoms 2189 (82.7) & ) Symptoms 459 (17.3) & Crude OR and $95 \% \mathrm{Cl}$ & $P$-value & OR and $95 \% \mathrm{Cl}$ & $P$-value \\
\hline $7-9$ & $85(3.9)$ & $15(3.3)$ & $0.790(0.449-1.392)$ & 0.415 & & \\
\hline$\geq 10$ & $23(1.1)$ & $4(0.9)$ & $0.779(0.267-2.272)$ & 0.647 & & \\
\hline \multicolumn{7}{|l|}{ Physical activity at work } \\
\hline Light (reference) & $1,248(57.0)$ & $279(60.8)$ & 1.00 & & & \\
\hline Missing & $77(3.5)$ & $21(4.6)$ & & & & \\
\hline \multicolumn{7}{|c|}{ Physical activity during leisure time } \\
\hline Sedentary/moderate (reference) & $354(16.2)$ & 79 (17.2) & 1.00 & & & \\
\hline Training regularly & $812(37.1)$ & $185(40.3)$ & $1.021(0.763-1.366)$ & 0.889 & & \\
\hline Missing & $1,023(46.7)$ & $195(42.5)$ & & & & \\
\hline
\end{tabular}

Gl, gastrointestinal; BMI, body mass index; OR, odds ratio; Cl, confidence interval.

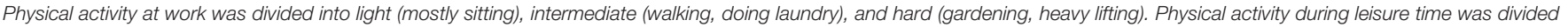

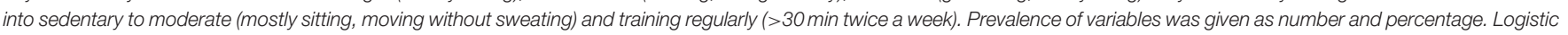

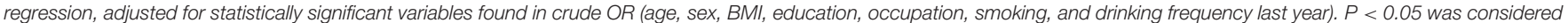
statistically significant.

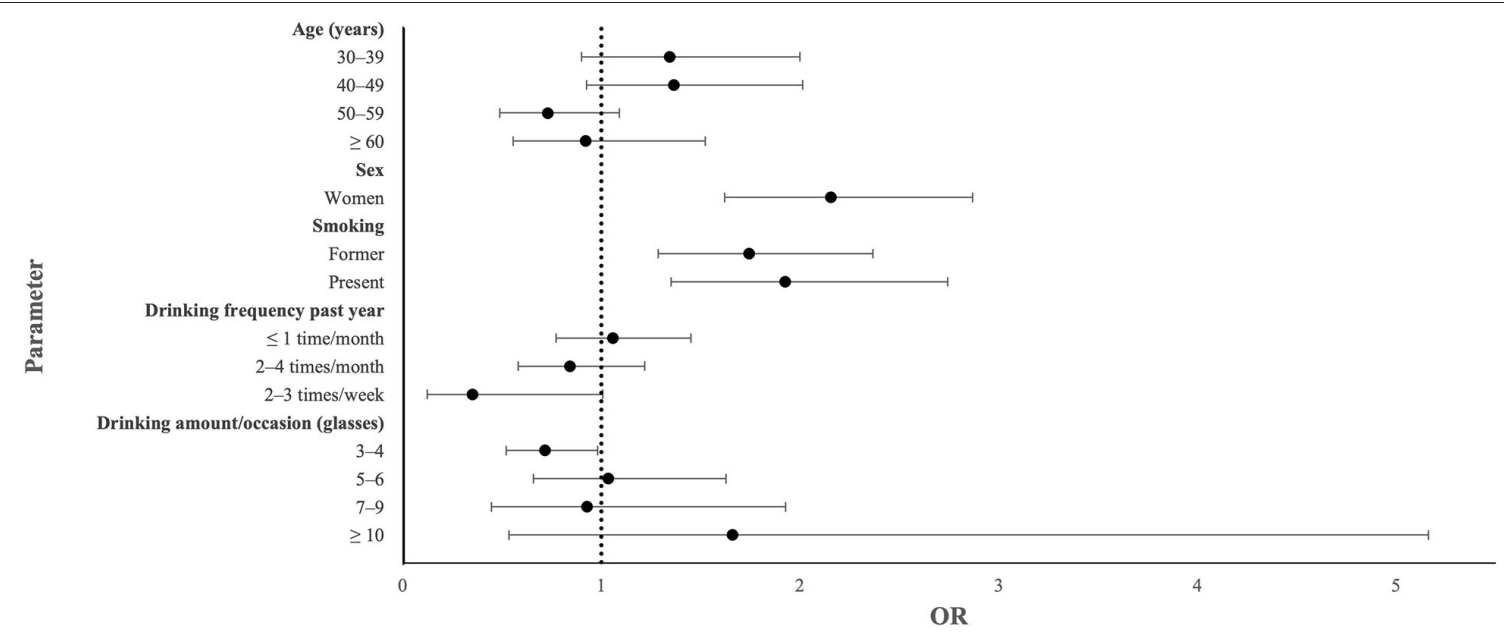

FIGURE 2 | Forest plot showing odds ratio (OR) and 95\% confidence interval in an adjusted model calculating sociodemographic parameters significantly associated with irritable bowel syndrome (IBS) in crude calculations.

observed was with being unemployed (Table 7). In women, there was a significant association between IBS and being present smoker (Table 6). GI symptoms were associated with former smoking and inversely associated with age $\geq 50$ years and intermediate physical activity at work (Table 7).

\section{DISCUSSION}

The main findings in the present population-based study were that IBS and GI symptoms the past 2 weeks were associated with female sex and smoking. Further, IBS was inversely associated with drinking moderate amount of alcohol and GI symptoms were associated with studying and unemployment and inversely associated with higher age. In men, IBS was associated with middle-age and both IBS and GI symptoms were associated with being unemployed. In women, IBS and GI symptoms were associated with present and former smoking, respectively, and GI symptoms were also inversely associated with higher age and intermediate physical activity at work. Thus, our hypothesis that smoking and snuff using have similar adverse impact on the GI symptoms and that higher alcohol consumption, living alone, lower BMI, lower education, and lower physical activity are associated with IBS or more symptoms could not be confirmed.

The female dominance in IBS is well-described in several studies $(2,7,13)$, and is also confirmed in the present study of the general population. The age was lower in the subjects with IBS and GI symptoms than in those without symptoms. Calculations stratified by sex showed that men were more prone to suffer from IBS in the middle-age, and women were less prone to have GI symptoms when they were elder. 


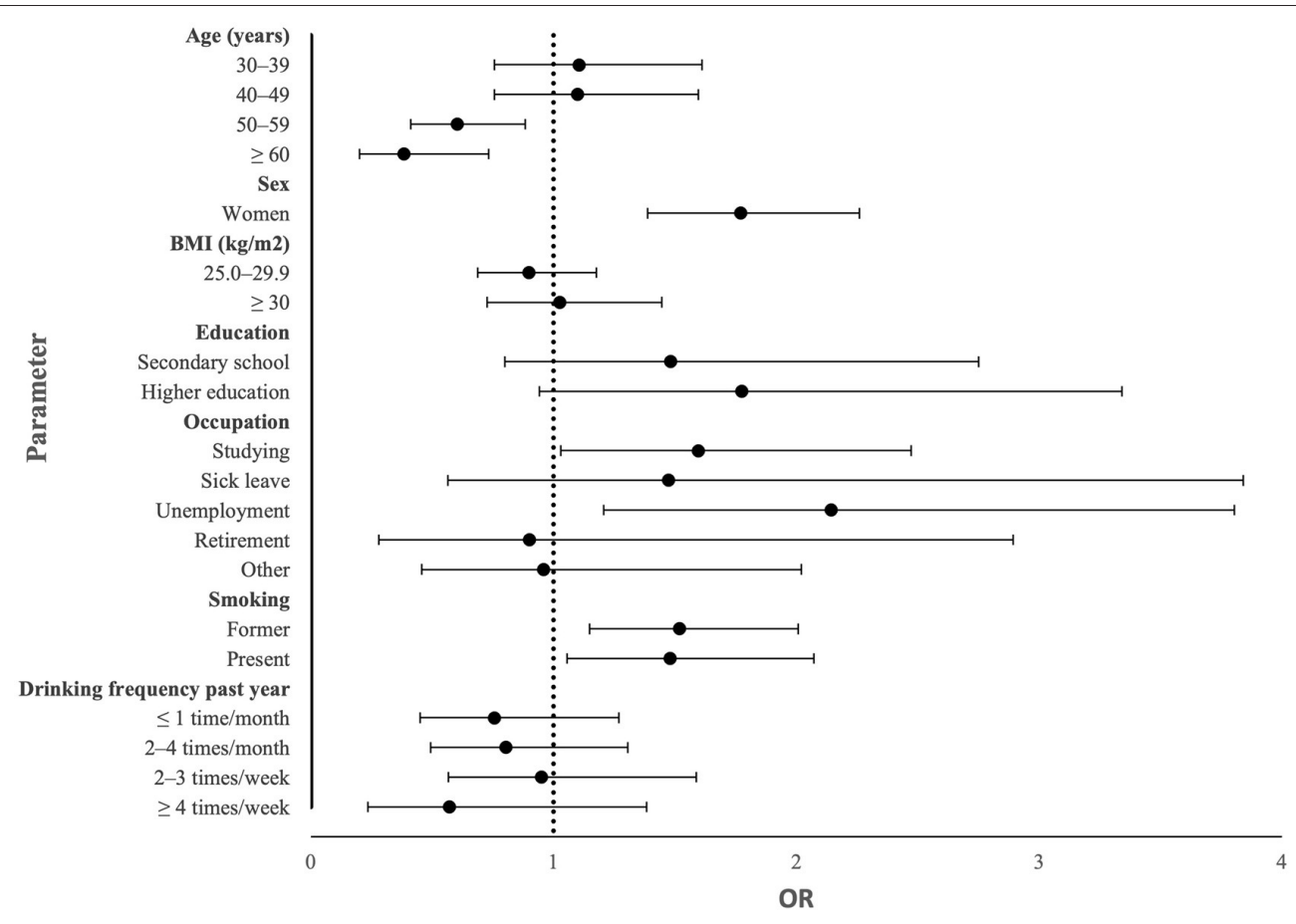

FIGURE 3 | Forest plot showing odds ratio (OR) and 95\% confidence interval in an adjusted model calculating sociodemographic parameters significantly associated with gastrointestinal symptoms in crude calculations.

In line with a previous population-based study in elderly, participants with IBS and GI symptoms had lower BMI than subjects without IBS and GI symptoms (11). However, when performing logistic regression and adjusting for confounders, no association between IBS or GI symptoms and BMI groups could be found. These differences in calculations may explain contradictory results from other studies regarding BMI and IBS (9-11). Neither marital status nor education did have any effect on IBS or GI symptoms, although this has been described in previous studies $(8,9)$.

Both current and former smoking were associated with IBS and GI symptoms, which is in line with previous research (13, $14,23,24)$. However, when examining the severity of individual GI symptoms, only present smoking was associated with the symptoms, except bloating and flatulence. The association with smoking was slightly stronger in this cohort than in a cohort of elder subjects from the general population (13). Smoking has been shown to be able to produce acute analgesic effect, which may improve abdominal pain and lead to continued smoking and poor motivation for smoking cessation (25). However, other studies have described how smoking may induce both visceral and peripheral hypersensitivity (26), which is supported by the strong association between abdominal pain and current smoking in the present study. Furthermore, IBS is associated with both diarrhea and/or constipation. Smoking has been found to delay the gastric emptying of solids in non-smokers, independently of nicotine (27). On the other hand, acute cigarette smoking in habitual smokers delayed mouth-cecum transit time, most likely due to nicotine (28). Transdermal nicotine application in non-smokers has been found to accelerate the transit time in the colon, sigmoideum, and rectum, and thereby decrease the total colon transit time (29). Male smokers, in contrast to female smokers, have prolonged colonic transit time compared to non-smokers in the same sex (30). These effects of smoking on GI motility may explain why smokers suffer from diarrhea and constipation. The association between smoking and functional abdominal pain may thus partly be explained by these alterations in motility (31). Although the role of smoking on gut microbiota is only rudimentary examined and may be influenced by weight and other lifestyle factors, studies suggest that smoking induces specific changes in the microbiome; changes that are reversed after smoking cessation (32). These changes of microbiota may also be of importance for the experience of IBS and GI symptoms $(2,32)$.

The difference between smoking and snuff using in association with IBS may depend on that cigarette smoking contain multiple toxins and cacogenic substances affecting the GI tract, which are not found to the same extent in snuff (33). Furthermore, the number of snuff users were lower, which may affect the calculations. When stratifying the results by sex, women but not men, had an association between smoking and both IBS and GI symptoms, even though there was no dependency found between sex and smoking in this cohort. The reason for this could be that the number of smoking men with IBS was too few. Generally, women tend to smoke more than men, while men tend to use snuff more (34). The latter was in line with the snuff habits in our cohort, but the smoking habits were equal between sexes. Snuff prevents smoking initiation and is used as a cessation aid, 
TABLE 5 | Associations between age, sex, occupation, and smoking and specific symptoms.

\begin{tabular}{|c|c|c|c|}
\hline Variables & $\beta$ & $95 \% \mathrm{Cl}$ & $P$-value \\
\hline \multicolumn{4}{|l|}{ Age } \\
\hline Psychological well-being & -2.029 & -26.48 to -1.410 & $<0.001$ \\
\hline \multicolumn{4}{|l|}{ Sex (men reference) } \\
\hline Abdominal pain & 9.859 & $4.820-14.897$ & $<0.001$ \\
\hline Constipation & 15.226 & $9.874-20.579$ & $<0.001$ \\
\hline Bloating and flatulence & 15.720 & $10.253-21.187$ & $<0.001$ \\
\hline Influence on daily life & 10.630 & $5.088-16.172$ & $<0.001$ \\
\hline Psychological well-being & 4.395 & $2.684-6.105$ & $<0.001$ \\
\hline \multicolumn{4}{|l|}{ Present smoking } \\
\hline Abdominal pain & 8.945 & $2.448-15.442$ & 0.007 \\
\hline Diarrhea & 11.971 & $5.180-18.761$ & 0.001 \\
\hline Constipation & 8.043 & $1.259-14.827$ & 0.020 \\
\hline Bloating and flatulence & 7.883 & $0.918-14.848$ & 0.027 \\
\hline Vomiting and nausea & 7.722 & $1.377-14.068$ & 0.017 \\
\hline Influence on daily life & 8.652 & $1.558-15.747$ & 0.017 \\
\hline Psychological well-being & 5.842 & $3.356-8.329$ & $<0.001$ \\
\hline \multicolumn{4}{|l|}{ Occupation } \\
\hline \multicolumn{4}{|l|}{ Working (reference) } \\
\hline \multicolumn{4}{|l|}{ Studying } \\
\hline Abdominal pain & 35.702 & $10.137-61.267$ & 0.006 \\
\hline Bloating and flatulence & 31.081 & $2.590-59.573$ & 0.033 \\
\hline Psychological well-being & -6.875 & -12.449 to -1.300 & 0.016 \\
\hline \multicolumn{4}{|l|}{ Sick leave } \\
\hline Abdominal pain & 27.802 & $4.897-50.707$ & 0.017 \\
\hline Constipation & 29.813 & $5.960-53.667$ & 0.014 \\
\hline Bloating and flatulence & 26.664 & $3.324-50.005$ & 0.025 \\
\hline Vomiting and nausea & 28.373 & $9.710-47.037$ & 0.003 \\
\hline Influence on daily life & 35.268 & $13.840-56.695$ & 0.001 \\
\hline Psychological well-being & 23.170 & $15.200-31.140$ & $<0.001$ \\
\hline \multicolumn{4}{|l|}{ Unemployment } \\
\hline Constipation & 11.719 & $2.582-20.855$ & 0.012 \\
\hline Vomiting and nausea & 17.324 & $9.403-25.245$ & $<0.001$ \\
\hline Psychological well-being & 5.280 & $1.964-8.595$ & 0.002 \\
\hline \multicolumn{4}{|l|}{ Retirement } \\
\hline Psychological well-being & 12.477 & $7.263-17.692$ & $<0.001$ \\
\hline \multicolumn{4}{|l|}{ Other } \\
\hline Vomiting and nausea & 17.290 & $1.069-33.511$ & 0.037 \\
\hline \multicolumn{4}{|c|}{$\begin{array}{l}\beta \text {, beta-value; Cl, confidence interval. Symptoms the past } 2 \text { weeks were assessed } \\
\text { by the visual analog scale for irritable bowel syndrome (VAS-IBS) where } 0 \mathrm{~mm} \text { means } \\
\text { no symptoms and } 100 \mathrm{~mm} \text { means maximal symptoms (20). Generalized linear model, } \\
\text { using variables significantly associated with Gl symptoms in the logistic regression. } \\
\text { Age groups was calculated as a continuous variable. } P<0.05 \text { was considered as } \\
\text { statistically significant. }\end{array}$} \\
\hline
\end{tabular}

making the users less likely to smoke $(34,35)$. This could be seen in this cohort as well, where there was a dependency between smoking and using snuff. Even though snuff contains tobacco and nicotine, it has a less negative overall impact on the health $(36,37)$.

Binge drinking has previously been reported to be associated with GI symptoms the day after drinking $(12,15)$, while light to moderate drinking did not show any association with symptoms
TABLE 6 | Associations between sociodemographic factors, lifestyle habits and IBS stratified by sex.

\begin{tabular}{|c|c|c|c|c|}
\hline \multirow[t]{2}{*}{ Variables } & \multicolumn{2}{|c|}{ Men } & \multicolumn{2}{|c|}{ Women } \\
\hline & $\begin{array}{c}\text { OR and } 95 \% \\
\mathrm{Cl}\end{array}$ & $P$-value & $\begin{array}{c}\text { OR and } 95 \% \\
\mathrm{Cl}\end{array}$ & $P$-value \\
\hline \multicolumn{5}{|l|}{ Age (years) } \\
\hline$<30$ (reference) & 1.000 & & & \\
\hline 30-39 & $\begin{array}{c}3.050 \\
(1.355-6.863)\end{array}$ & 0.007 & & \\
\hline $40-49$ & $\begin{array}{c}2.773 \\
(1.231-6.241)\end{array}$ & 0.014 & & \\
\hline $50-59$ & $\begin{array}{c}1.163 \\
(0.492-2.753)\end{array}$ & 0.731 & & \\
\hline$\geq 60$ & $\begin{array}{c}1.486 \\
(0.472-4.674)\end{array}$ & 0.498 & & \\
\hline \multicolumn{5}{|l|}{ Occupation } \\
\hline Working (reference) & 1.000 & & & \\
\hline Studying & $\begin{array}{c}1.161 \\
(0.364-3.705)\end{array}$ & 0.801 & & \\
\hline Sick leave & $\begin{array}{c}4.063(0.423- \\
38.991)\end{array}$ & 0.224 & & \\
\hline Unemployment & $\begin{array}{c}5.505(2.293- \\
13.218)\end{array}$ & $<0.001$ & & \\
\hline Retirement & $\begin{array}{c}1.115 \\
(0.203-6.112)\end{array}$ & 0.900 & & \\
\hline Other & $\begin{array}{c}4.936(1.656- \\
14.713)\end{array}$ & 0.004 & & \\
\hline \multicolumn{5}{|l|}{ Smoking } \\
\hline Never (reference) & & & 1.000 & \\
\hline Former & & & $\begin{array}{c}1.254 \\
(0.885-1.776)\end{array}$ & 0.203 \\
\hline Present & & & $\begin{array}{c}1.591 \\
(1.069-2.367)\end{array}$ & 0.022 \\
\hline \multicolumn{5}{|l|}{ Snuff using } \\
\hline Never (reference) & & & 1.000 & \\
\hline Former & & & $\begin{array}{c}1.892 \\
(0.883-4.051)\end{array}$ & 0.101 \\
\hline Present & & & $\begin{array}{c}1.122 \\
(0.505-2.492\end{array}$ & 0.777 \\
\hline
\end{tabular}

IBS, irritable bowel syndrome; $B M I$, body mass index; OR, odds ratio; $\mathrm{Cl}$, confidence interval. Logistic regression adjusted for statistically significant variables found in crude OR (age and occupation in men and smoking and snuff in women). $P<0.05$ was considered statistically significant.

$(12,14,15)$. Other studies have shown that $12-17 \%$ of those with IBS report alcohol intolerance, and 50\% restrain themselves from drinking (38-40). This can explain why the IBS prevalence was higher in non-users of alcohol (9). On the other hand, there is a strong association between poor psychological wellbeing and severe GI symptoms $(1,2)$, and people with more pain could also have a reason for more drinking, as alcohol is associated with calming and numbing effects (22). The present study showed weak inverse association between IBS and an alcohol consumption of 3-4 glasses per occasion. Taken together, the conclusion can be drawn that alcohol abuse is not responsible for the great burden of IBS or GI symptoms in the population. 
TABLE 7 | Association between sociodemographic factors, lifestyle habits and Gl symptoms past 2 weeks stratified by sex.

\begin{tabular}{|c|c|c|c|c|}
\hline \multirow[t]{2}{*}{ Variables } & \multicolumn{2}{|c|}{ Men } & \multicolumn{2}{|c|}{ Women } \\
\hline & OR $95 \% \mathrm{Cl}$ & $P$-value & OR $95 \% \mathrm{Cl}$ & $P$-value \\
\hline \multicolumn{5}{|l|}{ Age (years) } \\
\hline <30 (reference) & 1.000 & & 1.000 & \\
\hline 30-39 & $\begin{array}{c}1.420 \\
(0.793-2.543)\end{array}$ & 0.238 & $\begin{array}{c}0.944 \\
(0.582-1.531)\end{array}$ & 0.817 \\
\hline $40-49$ & $\begin{array}{c}1.299 \\
(0.718-2.347)\end{array}$ & 0.387 & $\begin{array}{c}0.959 \\
(0.603-1526)\end{array}$ & 0.859 \\
\hline $50-59$ & $\begin{array}{c}0.734 \\
(0.404-1.337)\end{array}$ & 0.312 & $\begin{array}{c}0.519 \\
(0.324-0.830)\end{array}$ & 0.006 \\
\hline$\geq 60$ & $\begin{array}{c}0.518 \\
(0.188-1.427)\end{array}$ & 0.203 & $\begin{array}{c}0.296 \\
(0.125-0.701)\end{array}$ & 0.006 \\
\hline \multicolumn{5}{|l|}{ BMI $\left(\mathrm{kg} / \mathrm{m}^{2}\right)$} \\
\hline <25 (reference) & 1.000 & & & \\
\hline $25.0-29.9$ & $\begin{array}{c}0.816 \\
(0.533-1.249)\end{array}$ & 0.349 & & \\
\hline$\geq 30$ & $\begin{array}{c}0.974 \\
(0.570-1.662)\end{array}$ & 0.922 & & \\
\hline \multicolumn{5}{|l|}{ Occupation } \\
\hline Working (reference) & 1.000 & 1.000 & & \\
\hline Studying & $\begin{array}{c}1.346 \\
(0.655-2.768)\end{array}$ & 0.419 & $\begin{array}{c}1.317 \\
(0.754-2.299)\end{array}$ & 0.333 \\
\hline Sick leave & - & - & $\begin{array}{c}0.647 \\
(0.140-2.985)\end{array}$ & 0.577 \\
\hline Unemployment & $\begin{array}{c}3.612 \\
(1.675-7.788)\end{array}$ & 0.001 & $\begin{array}{c}1.785 \\
(0.731-4.360)\end{array}$ & 0.203 \\
\hline Retirement & $\begin{array}{c}0.442 \\
(0.050-3.880)\end{array}$ & 0.461 & $\begin{array}{c}1.376 \\
(0.256-7.396)\end{array}$ & 0.710 \\
\hline Other & $\begin{array}{c}1.857 \\
(0.592-5.824)\end{array}$ & 0.289 & $\begin{array}{c}0.719 \\
(0.270-1.914)\end{array}$ & 0.509 \\
\hline \multicolumn{5}{|l|}{ Smoking } \\
\hline Never (reference) & & & 1.000 & \\
\hline Former & & & $\begin{array}{c}1.452 \\
(1.020-2.067)\end{array}$ & 0.038 \\
\hline Present & & & $\begin{array}{c}1.481 \\
(0.964-2.274)\end{array}$ & 0.073 \\
\hline \multicolumn{5}{|c|}{ Physical activity at work } \\
\hline Light (reference) & & & 1.000 & \\
\hline Intermediate & & & $\begin{array}{c}0.621(0.436- \\
0.885)\end{array}$ & 0.008 \\
\hline Hard & & & $\begin{array}{c}0.688 \\
(0.404-1.172)\end{array}$ & 0.169 \\
\hline
\end{tabular}

Gl, gastrointestinal; BMI, body mass index; OR, odds ratio; Cl, confidence interval.

Physical activity at work was divided into light (mostly sitting), intermediate (walking, doing laundry), and hard (gardening, heavy lifting). Logistic regression adjusted for statistically significant variables found in crude OR (age, BMI, and occupation, in men and age, occupation, smoking, and physical activity at work in women). $P<0.05$ was considered statistically significant.

Being unemployed was associated with GI symptoms, especially in men. Unemployment and "other" were also associated with IBS in men. The group other is a bit vague, but the question states that they are not working, but doing something else. Sick leave and unemployment were associated with more severe symptoms and impaired psychological wellbeing. This is in line with previous research showing a high degree of unemployment and absence from work in patients with self-reported IBS (41). While being unemployed, a social stigma can arise, and both being without a job and the fear of stigma can increase the stress levels (42). All type of stress is a wellknown factor associated with FGID (43). Research has found that men have worse mental health than women when they are unemployed and living with somebody else. This could be due to that men traditionally are considered as the family's main breadwinner, and to provide this is their primary responsibility (44). In line with this, the subjective social status relative to the others in the same country mediates the association between occupational status, mental health, and stress (45).

There was no difference in physical activity between subjects with IBS or GI symptoms and those without symptoms. Nevertheless, several studies have shown that physical inactivity is associated with FGID (11), and that physical activity may decrease symptoms (46). Thus, although physical activity has been proven to be of benefit for these patients, inactivity could probably not explain the development of the disease in the general population. The higher degree of education in women may explain the lower physical activity at work for women.

While comparing different studies, it is important to understand that there are variations in IBS definitions (e.g., different Rome criteria), affecting the inclusion criteria and cohort compositions $(3,4)$. Therefore, we chose to include the VAS-IBS recording all GI symptoms independent of classifications. This questionnaire is valid throughout decades, since it only assesses the symptoms, without any defined combinations of symptoms (20). The recruitment process of participants is also important. This study included participants originating from the general population and not from a hospital, which might otherwise be a common source. Also, the participants' age can vary, where previous research focuses more on younger participants (47), while the age in this cohort is more evenly spread in different age groups.

The major strength of this thesis is the large cohort of patients from the general population with validated questions of specific GI symptoms. It is also a strength that associations with snuff habits have been examined. One limitation was that the questionnaire was extensive, and participants may suffer from reading fatigue with several questions to answer. Selection of offspring to MCC-CC may render recall bias. Another limitation with the source material is the question regarding IBS since the Rome questionnaire was not completed depending on its size (48). However, IBS is a well-known description of GI symptoms in the society, and people are familiar with the symptoms and criteria (41). There is also a risk of missing newly debuted cases when asking for symptoms in the past, e.g., 6-12 months, which means that some of the data could be wrongly categorized. On the other hand, just to assess the GI symptoms during the past 2 weeks is also a limitation. When grouping by occupation, those who had selected multiple choices about their occupation was marked as missing, because it was not clearly stated their primary activity or distribution. The cohort was too small in some cases, and some groups had to be merged to get a reasonable volume to compare, which makes it possible that some details were lost. 
In conclusion, smoking seems to be a lifestyle habit which is clearly associated with IBS. Confirmation of this finding in several studies suggest that prevention of subjects to start smoking, and smoking cessation in smokers, are lifestyle habits important to promote. An awareness of the risk for unemployed men to suffer from IBS and GI symptoms is important to remember in daily clinical praxis. However, other sociodemographic factors and lifestyle habits assessed in this study are not the main reason for subjects to suffer from IBS and GI symptoms in the general population.

\section{DATA AVAILABILITY STATEMENT}

The raw data supporting the conclusions of this article will be made available by the authors, without undue reservation.

\section{ETHICS STATEMENT}

The studies involving human participants were reviewed and approved by Regional Ethics Review Board in Lund (2012/594). The patients/participants provided

\section{REFERENCES}

1. Canavan C, West J, Card T. The epidemiology of irritable bowel syndrome. Clin Epidemiol. (2014) 6:71-80. doi: 10.2147/CLEP.S40245

2. Lacy BE, Mearin F, Chang L, Chey WD, Lembo AJ, Simren M, et al. Bowel disorders. Gastroenterology. (2016) 150:1393407. doi: 10.1053/j.gastro.2016.02.031

3. Mearin F, Badia X, Balboa A, Baró E, Caldwell E, Cucala M, et al. Irritable bowel syndrome prevalence varies enormously depending on the employed diagnostic criteria: comparison of Rome II versus previous criteria in a general population. Scand J Gastroenterol. (2001) 36:115561. doi: 10.1080/00365520152584770

4. Whitehead WE, Palsson OS, Simrén M. Irritable bowel syndrome: what do the new Rome IV diagnostic guidelines mean for patient management? Expert Rev Gastroenterol Hepatol. (2017) 11:281-3. doi: 10.1080/17474124.2017.1292130

5. Longstreth GF, Wilson A, Knight K, Wong J, Chiou CF, Barghout $\mathrm{V}$, et al. Irritable bowel syndrome, health care use, and costs: a U.S. managed care perspective. Am J Gastroenterol. (2003) 98:6007. doi: 10.1111/j.1572-0241.2003.07296.x

6. Maxion-Bergemann S, Thielecke F, Abel F, Bergemann R. Costs of irritable bowel syndrome in the UK and US. Pharmacoeconomics. (2006) 24:2137. doi: 10.2165/00019053-200624010-00002

7. Lovell RM, Ford AC. Global prevalence of and risk factors for irritable bowel syndrome: a meta-analysis. Clin Gastroenterol Hepatol. (2012) 10:71221. doi: 10.1016/j.cgh.2012.02.029

8. Farzaneh N, Ghobaklou M, Moghimi-Dehkordi B, Naderi N, Fadai F. Effects of demographic factors, body mass index, alcohol drinking and smoking habits on irritable bowel syndrome: a case control study. Ann Med Health Sci Res. (2013) 3:391-6. doi: 10.4103/2141-9248.117958

9. Navok R, Dimitrova-Yurukova D, Snegarova V, Uzunova M, Lyutakov I, Ivanova $\mathrm{M}$, et al. Prevalence of irritable bowel syndrome, functional dyspepsia and their overlap in Bulgaria: a population-based study. J Gastrointestin Liver Dis. (2020) 29:329-38. doi: 10.15403/jgld-2645

10. Le Pluart D, Sabaté JM, Bouchoucha M, Hercberg S, Benamouzig R, Julia C. Functional gastrointestinal disorders in 35447 adults and their association with body mass index. Aliment Pharmacol Ther. (2015) 41:75867. doi: 10.1111/apt.13143 their written informed consent to participate in this study.

\section{AUTHOR CONTRIBUTIONS}

DN and BO were responsible for study design, acquisition of data, statistical analysis, interpretation of data, and drafting the manuscript. DN was responsible for visualization. BO obtained funding. Both authors contributed to the article and approved the submitted version.

\section{FUNDING}

The study was financed by the Development Foundation of Region Skåne [grant numbers REGSKANE-818781, 2018Projekt0024].

\section{ACKNOWLEDGMENTS}

We want to acknowledge Anders Dahlin for data management and the staff at the Clinical Research Center at Skåne University Hospital, Malmö, for recruitment of participants.

11. Ohlsson B, Manjer J. Physical inactivity during leisure time and irregular meals are associated with functional gastrointestinal complaints in middle-aged and elder subjects. Scand J Gastroenterol. (2016) 51:1299-307. doi: 10.1080/00365521.2016.1209786

12. Ohlsson B. The role of smoking and alcohol behaviour in management of functional gastrointestinal disorders. Best Pract Res Clin Gastroenterol. (2017) 31:545-52. doi: 10.1016/j.bpg.2017.09.006

13. Lundström O, Manjer J, Ohlsson B. Smoking is associated with several functional gastrointestinal symptoms. Scand J Gastroenterol. (2016) 51:91422. doi: 10.1080/00365521.2016.1174878

14. Nam SY, Kim BC, Ryu KH, Park BJ. Prevalence and risk factors of irritable bowel syndrome in healthy screenee undergoing colonoscopy and laboratory tests. J Neurogastroenterol Motil. (2010) 16:47-51. doi: 10.5056/jnm.2010.16.1.47

15. Reding KW, Cain KC, Jarrett ME, Eugenio MD, Heitkemper MM. Relationship between patterns of alcohol consumption and gastrointestinal symptoms among patients with irritable bowel syndrome. Am J Gastroenterol. (2013) 108:270-6. doi: 10.1038/ajg.2012.414

16. Berglund G, Elmstahl S, Janzon L, Larsson SA. The Malmo diet and cancer study. Design and feasibility. J Intern Med. (1993) 233:45-51.

17. Smith JG, Newton-Cheh C, Almgren P, Struck J, Morgenthaler NG, Bergmann A, et al. Assessment of conventional cardiovascular risk factors and multiple biomarkers for the prediction of incident heart failure and atrial fibrillation. J Am Coll Cardiol. (2010) 56:1712-9. doi: 10.1016/j.jacc.2010. 05.049

18. Brunkwall L, Jönsson D, Ericson U, Hellstrand S, Kennbäck C, Östling G, Jujic A, et al. The Malmö Offspring Study (MOS): design, methods and first results. Eur J Epidemiol. (2020) 36:103-16. doi: 10.1007/s10654-020-00695-4

19. Longstreth GF, Thompson WG, Chey WD, Houghton LA, Mearin F, Spiller RC. Functional bowel disorders. Gastroenterology. (2006) 130:148091. doi: 10.1053/j.gastro.2005.11.061

20. Bengtsson M, Ohlsson B, Ulander K. Development and psychometric testing of the Visual Analogue Scale for Irritable Bowel Syndrome (VAS-IBS). BMC Gastroenterol. (2007) 7:16. doi: 10.1186/1471-230X-7-16

21. Obesity: Preventing and Managing the Global Epidemic. Report of a WHO consultation. World Health Organization Technical Report Series (2000) 894:i-xii, 1-253. 
22. Nam HW, McIver SR, Hinton DJ, Thakkar MM, Sari Y, Parkinson FE, et al. Adenosine and glutamate signaling in neuron-glial interactions: implications in alcoholism and sleep disorders. Alcohol Clin Exp Res. (2012) 36:111725. doi: 10.1111/j.1530-0277.2011.01722.x

23. Parry SD, Barton JR, Welfare MR. Factors associated with the development of post-infectious functional gastrointestinal diseases: does smoking play a role? Eur J Gastroenterol Hepatol. (2005) 17:1071-5. doi: 10.1097/00042737-200510000-00010

24. Kang SH, Choi SW, Lee SJ, Chung WS, Lee HR, Chung KY, et al. The effects of lifestyle modification on symptoms and quality of life in patients with irritable bowel syndrome: a prospective observational study. Gut Liver. (2011) 5:472-7. doi: 10.5009/gnl.2011.5.4.472

25. Zale E, Maisto S, Ditre J. Anxiety and depression in bidirectional relations between pain and smoking: implications for smoking cessation. Behav Modif. (2015) 40:7-28. doi: 10.1177/0145445515610744

26. Pisinger C, Aadahl M, Toft U, Birke H, Zytphen-Adeler J, Jørgensen T. The association between active and passive smoking and frequent pain in a general population. Eur J Pain. (2011) 15:77-83. doi: 10.1016/j.ejpain.2010.05.004

27. Miller G, Palmer KR, Smith B, Ferrington C, Merrick MV. Smoking delays gastric emptying of solids. Gut. (1989) 30:50-3. doi: 10.1136/gut.30.1.50

28. Scott AM, Kellow JE, Eckersley GM, Nolan JM, Jones MP. Cigarette smoking and nicotine delay postprandial mouth-cecum transit time. Dig Dis Sci. (1992) 37:1544-7. doi: 10.1007/BF01296500

29. Rausch T, Beglinger C, Alam N, Gyr K, Meier R. Effect of transdermal application of nicotine on colonic transit in healthy nonsmoking volunteers. Neurogastroenterol Motil. (1998) 10:263-70. doi: 10.1046/j.1365-2982.1998.00105.x

30. Meier R, Beglinger C, Dederding JP, Meyer-Wyss B, Fumagalli M, Rowedder A, et al. Influence of age, gender, hormonal status and smoking habits on colonic transit time. Neurogastroenterol Motil. (1995) 7:23558. doi: 10.1111/j.1365-2982.1995.tb00231.x

31. Tuteja AK, Talley NJ, Joos SK, Tolman KG, Hickam DH. Abdominal bloating in employed adults: prevalence, risk factors, and association with other bowel disorders. Am J Gastroenterol. (2008) 103:1241-8. doi: 10.1111/j.1572-0241.2007.01755.x

32. Zawertailo L, Attwells S, deRuiter WK, Lan Le T, Dawson D, Selby P. Food addiction and tobacco use disorder: common liability and shared mechanisms. Nutrients. (2020) 12:3834. doi: 10.3390/nu121 23834

33. Li LF, Chan RL, Lu L, Shen J, Zhang L, Wu WK, et al. Cigarette smoking and gastrointestinal diseases: the causal relationship and underlying molecular mechanisms (review). Int J Mol Med. (2014) 34:372-80. doi: 10.3892/ijmm.2014.1786

34. The World Bank. Curbing the epidemic: governments and the economics of tobacco control. World Bank Tob Control. (1999) 8:196-201.

35. Caponnetto P, Keller E, Bruno CM, Polosa R. Handling relapse in smoking cessation: strategies and recommendations. Intern Emerg Med. (2013) 8:712. doi: $10.1007 / \mathrm{s} 11739-012-0864-\mathrm{Z}$

36. Roth HD, Roth AB, Liu X. Health risks of smoking compared to Swedish snus. Inhal Toxicol. (2005) 17:741-8.

37. Clarke E, Thompson K, Weaver S, Thompson J, O'Connell G. Snus: a compelling harm reduction alternative to cigarettes. Harm Reduct J. (2019) 16:62. doi: 10.1186/s12954-019-0335-1

38. Simren M, Mansson A, Langkilde AM, Svedlund J, Abrahamsson H, Bengtsson $\mathrm{U}$, et al. Food-related gastrointestinal symptoms in the irritable bowel syndrome. Digestion. (2001) 63:108-15. doi: 10.1159/00005 1878

39. Monsbakken KW, Vandvik PO, Farup PG. Perceived food intolerance in subjects with irritable bowel syndrome- etiology, prevalence and consequences. Eur J Clin Nutr. (2006) 60:667-72. doi: 10.1038/sj.ejcn.160 2367

40. Swanson GR, Sedghi S, Farhadi A, Keshavarzian A. Pattern of alcohol consumption and its effect on gastrointestinal symptoms in inflammatory bowel disease. Alcohol. (2010) 44:223-8. doi: 10.1016/j.alcohol.2009. 10.019

41. Van den Houte K, Carbone F, Pannemans J, Corsetti M, Fischler B, Piessevaux $\mathrm{H}$, et al. Prevalence and impact of self-reported irritable bowel symptoms in the general population. UEG J. (2019) 7:30715. doi: $10.1177 / 2050640618821804$

42. O'Donnell AT, Corrigan F, Gallagher S. The impact of anticipated stigma on psychological and physical health problems in the unemployed group. Front Psychol. (2015) 6:1263. doi: 10.3389/fpsyg.2015.01263

43. Popa SL, Leucuta DC, Dumitrascu DL. Pressure management as an occupational stress risk factor in irritable bowel syndrome. Medicine. (2018) 97:e13562. doi: 10.1097/MD.0000000000013562

44. Artazcoz L, Benach J, Borrell C, Cortès I. Unemployment and mental health: understanding the interactions among gender, family roles, and social class. Am J Public Health. (2004) 94:82-8. doi: 10.2105/AJPH.94.1.82

45. Neubert M, Süssenbach P, Rief W, Euteneuer F. Unemployment and mental health in the German population: the role of subjective social status. Psychol Res Behav Manag. (2019) 12:557-64. doi: 10.2147/PRBM.S207971

46. Johannesson E, Simren M, Strid H, Bajor A, Sadik R. Physical activity improves in irritable bowel syndrome: a randomized controlled trial. Am J Gastroenterol. (2011) 106:915-22. doi: 10.1038/ajg.2010.480

47. Quigley EM, Fried M, Gwee KA, Khalif I, Hungin AP, Lindberg G, et al. World gastroenterology organisation global guidelines irritable bowel syndrome: a global perspective update september 2015. J Clin Gastroenterol. (2016) 50:704-13. doi: 10.1097/MCG.0000000000000653

48. Palsson OS, Whitehead WE, Van Tilburg MAL, Chang L, Chey W, Crowell MD, et al. Development and validation of the Rome IV diagnostic questionnaire for adults. Gastroenterology. (2016) 150:148191. doi: 10.1053/j.gastro.2016.02.014

Conflict of Interest: The authors declare that the research was conducted in the absence of any commercial or financial relationships that could be construed as a potential conflict of interest.

Publisher's Note: All claims expressed in this article are solely those of the authors and do not necessarily represent those of their affiliated organizations, or those of the publisher, the editors and the reviewers. Any product that may be evaluated in this article, or claim that may be made by its manufacturer, is not guaranteed or endorsed by the publisher.

Copyright (C) 2021 Nilsson and Ohlsson. This is an open-access article distributed under the terms of the Creative Commons Attribution License (CC BY). The use, distribution or reproduction in other forums is permitted, provided the original author(s) and the copyright owner(s) are credited and that the original publication in this journal is cited, in accordance with accepted academic practice. No use, distribution or reproduction is permitted which does not comply with these terms. 